\title{
Learning and hippocampal synaptic plasticity in streptozotocin-diabetic rats: interaction of diabetes and ageing
}

\author{
A. Kamal ${ }^{1}$, G.J. Biessels ${ }^{2}$, S. E. J.Duis ${ }^{1}$, W.H. Gispen ${ }^{1}$ \\ ${ }^{1}$ Department of Medical Pharmacology, Rudolf Magnus Institute for Neuroscience, University Medical Centre Utrecht, \\ The Netherlands \\ ${ }^{2}$ Department of Neurology, Rudolf Magnus Institute for Neurosience, University Medical Centre Utrecht, The Netherlands
}

\section{Abstract}

Aims/hypothesis. Diabetes mellitus leads to functional and structural changes in the brain which appear to be most pronounced in the elderly. Because the pathogenesis of brain ageing and that of diabetic complications show close analogies, it is hypothesized that the effects of diabetes and ageing on the brain interact. Our study examined the effects of diabetes and ageing on learning and hippocampal synaptic plasticity in rats.

Methods. Young adult (5 months) and aged (2 years) rats were examined after 8 weeks of streptozotocindiabetes. Learning was tested in a Morris water maze. Synaptic plasticity was tested ex vivo, in hippocampal slices, in response to trains of stimuli of different frequency $(0.05$ to $100 \mathrm{~Hz})$.

Results. Statiscally significant learning impairments were observed in young adult diabetic rats compared with controls. These impairments were even greater in aged diabetic animals. In hippocampal slices from young adult diabetic animals long-term potentiation induced by $100 \mathrm{~Hz}$ stimulation was impaired compared with controls (138 vs $218 \%$ of baseline). In contrast, long-term depression induced by $1 \mathrm{~Hz}$ stimulation was enhanced in slices from diabetic rats compared with controls (79 vs $92 \%$ ). In non-diabetic aged rats synaptic responses were 149 and $93 \%$ of baseline in response to 100 and $1 \mathrm{~Hz}$ stimulation, compared with 106 and $75 \%$ in aged diabetic rats.

Conclusion/interpretation. Both diabetes and ageing affect learning and hippocampal synaptic plasticity. The cumulative deficits in learning and synaptic plasticity in aged diabetic rats indicate that the effects of diabetes and ageing on the brain could interact. [Diabetologia (2000) 43: 500-506]

Keywords Ageing, diabetes mellitus, brain, learning, water maze, hippocampus, synaptic plasticity.
Peripheral neuropathy is a well-known complication of both clinical and experimental diabetes mellitus. Long-term diabetes also leads to a variety of discrete functional and structural disorders in the central nervous system [1]. Moderate impairment of cognitive

Received: 18 October 1999 and in revised form: 6 December 1999

Corresponding author: Dr W.H. Gispen, Rudolf Magnus Institute for Neuroscience, Department of Medical Pharmacology, P. O. Box 80040, 3508 TA, Utrecht, The Netherlands Abbreviations: fEPSP, Field excitatory post synaptic potential; HFS, high-frequency stimulation; LFS, low-frequency stimulation; LTD, long-term depression; LTP, long-term potentiation; STZ, streptozotocin; ANOVAR, one-way analysis of variance for repeated measures. function has been observed in middle-aged adults with Type I (insulin-dependent) or Type II (non-insulin-dependent) diabetes mellitus. In the elderly cognitive deficits appear, however, to be more pronounced and can readily be detected with relatively crude tests such as the mini-mental state examination $[4,5]$.

The hippocampus is a brain structure involved in certain forms of learning [6, 7]. At the cellular level, hippocampal long-term potentiation (LTP) and depression (LTD) are two forms of synaptic plasticity which have attracted considerable attention in the search for the mechanisms of learning and memory $[8,9]$. We have shown previously that LTP expression was impaired in the CA1 and the CA3 field of the hippocampus of young adult diabetic rats, whereas LTD expression in the CA1 field was enhanced [10, 
11]. The degree of the LTP deficit was related to the severity of hyperglycaemia [10] and diabetes duration [11]. These alterations in synaptic plasticity were associated with learning impairments in a Morris-water maze $[10,12]$. An association between alterations in hippocampal LTP and learning impairments has also been reported in ageing animals [13] and in response to various pharmacological and molecular manipulations $[14,15]$, supporting the functional relevance of the link between these two variables.

The aim of the present study was to examine learning and hippocampal synaptic plasticity in ageing and diabetes, based on the hypothesis that the effects of diabetes and ageing on the brain could interact. This hypothesis stems from clinical observations that the effects of diabetes on the brain are most pronounced in the elderly [16]. Moreover, many of the processes which have been implicated in the pathogenesis of brain ageing, in particular oxidative stress, microvascular dysfunction, non-enzymatic protein glycation and disturbed intracellular calcium homeostasis $[17,18]$, are also implicated in the development of diabetic complications $[17,19]$. To find the possible interaction between diabetes and ageing, we investigated Morris water maze performance and examined hippocampal synaptic plasticity ex vivo in young adult and aged diabetic and non-diabetic rats. Because the study aimed to examine the additive effects of diabetes and ageing on the brain, an experimental protocol was chosen in which each of these two conditions in isolation produces only moderate deficits. Rats were examined after 2 months of diabetes, which produces half-maximum deficits in synaptic plasticity in young adult rats [11]. Aged rats were examined at 2 years of age, when they have developed moderate changes in synaptic plasticity due to aging alone.

\section{Materials and methods}

Experimental design. In experiment 1 the effect of diabetes on learning and hippocampal synaptic plasticity was studied in young adult animals. Experiment 2 evaluated the effects of diabetes on these variables in aged animals. In each experiment there was a diabetic group and a non-diabetic control group matched for age. Diabetes duration was identical in both experiments.

After 8 weeks of diabetes, rats were tested in a water maze. Next synaptic plasticity was measured in hippocampal slices. In experiment 1,18 young adult animals were used and 9 of each group were tested in the Morris maze. Electrophysiology of the hippocampus was done in 8 animals from each group. In experiment 2, 15 animals were tested of which 7 were diabetic and 8 controls. In this experiment 2 of the control animals were not included in the analysis of the Morris maze test because they jumped out of the swimming pool. Electrophysiology of the hippocampus was done in all animals.

Animals. At the start of the experiment young adult male Wistar rats were 3 months old and weighed approximately $350 \mathrm{~g}$. Aged rats were 22 months old and weighed approximately
$650 \mathrm{~g}$. At this age $30-35 \%$ of rats of our strain had died spontaneously, mostly from an age of 16 months onwards. This percentage of spontaneous death gives an indication of the advanced age of the animals that entered the experiment. In experiment 2, 24 animals participated at 22 months of age (11 controls and 13 diabetic). Of these animals 9 died before the final measurements, 3 in the non-diabetic group and 6 in the diabetic group. Of the 6 diabetic animals 4 died within a week after diabetes induction.

Diabetes was induced by an i.v. injection of streptozotocin (STZ) (Serva Feinbiochemica, Heidelberg. Germany), dissolved in saline. The dose of STZ in young adult rats was $33 \mathrm{mg} / \mathrm{kg}$ body weight as a single injection. In the aged animals a modified diabetes induction protocol was used because their sensitivity to the toxic effects of STZ is increased (own observation in pilot studies) and a dose of $33 \mathrm{mg} / \mathrm{kg}$ proved to be fatal. The first i.v. dose of STZ in aged rats was $15 \mathrm{mg} /$ $\mathrm{kg}$ body weight. Blood samples were obtained by tail prick 2 days after STZ injection, and blood glucose determined by a strip-operated blood glucose sensor (companion2, Medisense, Birmingham, UK). A second STZ dose was given to rats that had blood glucose concentrations of $10-15 \mathrm{mmol} / \mathrm{l}$ $(15 \mathrm{mg} / \mathrm{kg}, n=4)$ or less than $10 \mathrm{mmol} / \mathrm{l}(20 \mathrm{mg} / \mathrm{kg}, n=4)$. Eventually a third dose of 20 or $25 \mathrm{mg} / \mathrm{kg}$ was given to animals that had blood glucose concentrations of 10-15 $(n=3)$ or less than $10 \mathrm{mmol} / \mathrm{l}(n=1)$, respectively. One animal was given a fourth dose of $20 \mathrm{mg} / \mathrm{kg}$. Rats were housed on sawdust and maintained on a $12 \mathrm{~h}: 12 \mathrm{~h}$ light:dark cycle. All rats were given free access to food and water. Body weight and blood glucose were determined weekly. In addition, measurements of fasting blood glucose (after $5 \mathrm{~h}$ of fasting), oral glucose tolerance and $\mathrm{HbA}_{1}$ values $\left(\mathrm{HbA}_{1}\right.$, test-kit, Sigma Diagnostics, St. Louis, Mo., USA) were used to monitor diabetes. The oral glucose tolerance test was done by giving the animals $2 \mathrm{~g} / \mathrm{kg} 30 \%$ glucose solution orally after $5 \mathrm{~h}$ of fasting. Blood glucose was measured after 30 and $60 \mathrm{~min}$. The principles of animal care were followed, and all experiments were approved by the Utrecht University Ethics Committee on animal experimentation.

Morris water maze. The water maze consisted of a large circular black pool $[210 \mathrm{~cm}$ diameter, $50 \mathrm{~cm}$ height, filled to a depth of $30 \mathrm{~cm}$ with water $\left.\left(28 \pm 1^{\circ} \mathrm{C}\right)\right]$ in which a submerged platform was hidden on a fixed location. The rat could climb onto the platform to emerge from the water and escape from the necessity of swimming. During a series of trials, each rat was trained to locate the platform.

On 5 consecutive days, the animals were given three acquisition trials each day. Because the performance of aged rats was seriously impaired, they were trained for 8 consecutive days. The pool was placed in a darkened room, illuminated only by sparse red light. Because impaired visual acuity might affect performance in diabetic and aged rats, a curtain around the water maze obscured visual cues. Each rat was given a maximum of $120 \mathrm{~s}$ to find the hidden platform (black, round, $8 \mathrm{~cm}$ diameter, $1 \mathrm{~cm}$ below surface, located $55 \mathrm{~cm}$ from the edge of the pool) and was allowed to stay on the platform for $30 \mathrm{~s}$. Rats that failed to locate the platform were put on it by the experimenter. The position of the rat in the pool was automatically registered by a video computer system (Noldus, Wageningen, The Netherlands). Both latency times and distances swum to reach the platform were measured.

On the final day of the training rats were tested in the water maze with a visible platform on a new location. The test with the visible platform does not require spatial orientation [20] and was used to show possible deficits in sensorimotor processes. Rats were allowed to swim for $60 \mathrm{~s}$. 


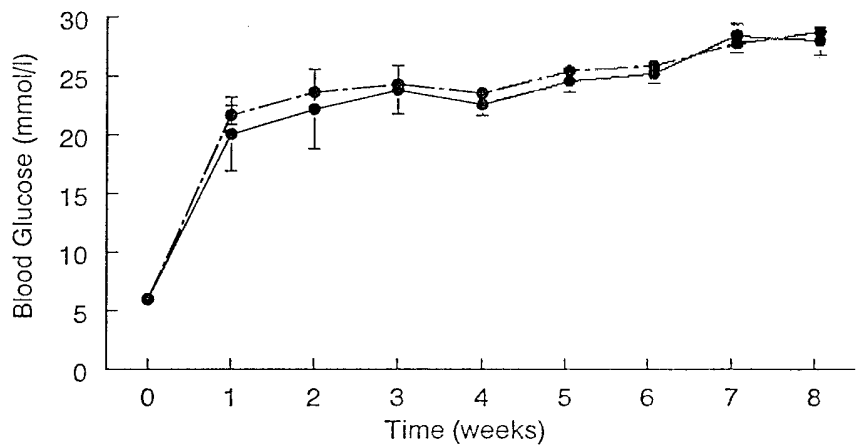

Fig. 1. Blood glucose concentrations in young (interrupted line) and aged (continuos line) diabetic animals during the course of the experiment. No difference was observed between the two groups

Electrophysiology. Transverse hippocampal slices $(450 \mu \mathrm{m}$ thick) were prepared as described elsewhere [10] and maintained in a submerged recording chamber and perfused (1-2 $\mathrm{ml} / \mathrm{min}$ ) with artificial cerebrospinal fluid of the following composition in mmol/l: $124 \mathrm{NaCl} ; 3.3 \mathrm{KCl} ; 1.2 \mathrm{KH}_{2} \mathrm{PO}_{4} ; 1.3$ $\mathrm{MGSO}_{4}, 10.0$ glucose, $20.0 \mathrm{NaHCO}_{3}$ and $2.5 \mathrm{CaCl}_{2}$ and gassed with $95 \% \mathrm{O}_{2}$, and $\mathrm{CO}_{2}$. All experiments were done at $30^{\circ} \mathrm{C}$ and after allowing the slices to recover for at least $60 \mathrm{~min}$ after preparation.

Field excitatory post synaptic potentials (fEPSPs) were recorded in the stratum radiatum with glass micro electrodes with a tip diameter of approximately $2 \mu \mathrm{m}$, filled with the incubation medium. Bipolar stainless-steel stimulation electrodes, insulated except for the tip (Clark, Electro medical instruments, Pangbour, UK), were placed on the afferent fibres of the stratum radiatum of the CA1 region of the hippocampus. Only those slices in which the amplitude of the fEPSP was $1 \mathrm{mV}$ or more at maximum response were included in the experiment.

Before each experiment the stimulus intensity to elicit a threshold and maximum fEPSPs were determined. Next, a stimulus-response relation was determined and the stimulus intensity was adjusted to evoke fEPSPs of half maximum amplitude, and kept constant thereafter. Stimulation frequency was $0.05 \mathrm{~Hz}$. The first $15 \mathrm{~min}$ of every recording served to obtain a baseline value. The average slope of the fEPSP at baseline was set at $100 \%$ and changes in slope were expressed as a change from baseline.

To plot the frequency response function of the hippocampal synapses, 900 pulses were given in different frequencies to the afferent fibres of CA1 fields, at frequencies from 0.05 to $100 \mathrm{~Hz}$. The responses were recorded for $30 \mathrm{~min}$ after the application of the conditioning stimuli [21]. High-frequency stim- ulation (HFS) $(100 \mathrm{~Hz}$ for $1 \mathrm{~s}$ and $50 \mathrm{~Hz}$ for $2 \mathrm{~s})$ was applied with intervals of $10 \mathrm{~s}$. Low-frequency stimulation (LFS) was given as a single train of 900 stimuli at $10 \mathrm{~Hz}$ (for $1.5 \mathrm{~min}$ ), $5 \mathrm{~Hz}$ (for $3 \mathrm{~min}$ ) or $1 \mathrm{~Hz}$ (for $15 \mathrm{~min}$ ).

Statistical analysis. Data are presented as means \pm SEM. Between group differences in body weight, blood glucose, and glucose tolerance test were analysed by two-tailed $t$ test for independent samples. For each measure of plasticity, the effect of LFS or HFS were analysed within each group by comparing the absolute values of the slope of the fEPSP before and 30 min after stimulation with a Wilcoxon matched-pairs signed test. Between each group differences in LTP and LTD expression were analysed by two-tailed $t$ test for independent samples. Between group differences in Morris-water maze performance were analysed by one-way analysis of variance for repeated measures (ANOVAR).

\section{Results}

Animals. In both age groups body weight and blood glucose were measured throughout the experiment. Blood glucose concentrations of young adult and aged diabetic rats were similar (Fig.1). Both young adult and aged diabetic animals showed significantly reduced body weight, together with increased plasma glucose concentrations and $\mathrm{HbA}_{1}$ values (Table 1 ). Fasting blood glucose concentrations as well as blood glucose 30 and 60 min after an oral glucose load were similar in young adult and aged diabetic rats (Table 1).

\section{Morris-water maze}

Experiment 1. In young adult control rats the latency and distance swum to reach the platform decreased gradually during the 5 days of training (Fig. 2). Performance was impaired in diabetic rats (day 1-5: latencies: $p<0.05$; distance: $p=0.12$ ). Distances swum to reach the platform were higher in diabetic animals than in controls during the final 3 days of the testing $(p<0.05)$. Performance of diabetic and non-diabetic rats in the trial with the visible platform was similar (latencies $29.1 \pm 6.4$ and $33.4 \pm 6.1 \mathrm{~s}$; distances $4.2 \pm$ 0.6 and $4.9 \pm 0.8 \mathrm{~m}$, in control and diabetes rats, respectively).

Table 1. Body weight, blood glucose, $\mathrm{HbA}_{1}$, fasting blood glucose (FBG) and oral glucose tolerance test (OGTT) in the young $(n=9)$ and aged (control $n=8$; diabetic: $n=7)$ rats

\begin{tabular}{|c|c|c|c|c|c|c|c|c|c|}
\hline & & \multicolumn{2}{|c|}{ Body weight (gram) } & \multicolumn{2}{|c|}{ Blood glucose $(\mathrm{mmol} / \mathrm{l})$} & \multirow{2}{*}{$\frac{\mathrm{HbA}_{1}(\%)}{\text { Week } 8}$} & \multicolumn{3}{|c|}{ Glucose tolerance test $(\mathrm{mmol} / \mathrm{l})$} \\
\hline & & Week 0 & Week 8 & Week 0 & Week 8 & & FBG & $\begin{array}{l}\text { OGTT } \\
\text { (after } 30 \mathrm{~min})\end{array}$ & $\begin{array}{l}\text { OGTT } \\
\text { (after } 60 \mathrm{~min} \text { ) }\end{array}$ \\
\hline Aged & $\begin{array}{l}\text { Control } \\
\text { Diabetic }\end{array}$ & $\begin{array}{l}650.5 \pm 3.9 \\
681.5 \pm 5.1\end{array}$ & $\begin{array}{c}654 \pm 17 \\
560.1 \pm 1.1\end{array}$ & $6.2 \pm 1.6$ & $\begin{array}{r}6.0 \pm 1.0 \\
28.5 \pm 1.2\end{array}$ & $\begin{array}{r}5.1 \pm 0.25 \\
10.1 \pm 0.16\end{array}$ & $\begin{array}{r}4.5 \pm 0.6 \\
18.1 \pm 2.4\end{array}$ & $\begin{array}{r}6.9 \pm 0.6 \\
24.5 \pm 2.4\end{array}$ & $\begin{array}{r}6.7 \pm 0.6 \\
25.6 \pm 2.3\end{array}$ \\
\hline
\end{tabular}

$T$ test analysis showed significant $(p<0.001)$ weight loss, increased blood glucose concentration and HbA $\mathrm{A}_{1}$ values in the diabetic animals 

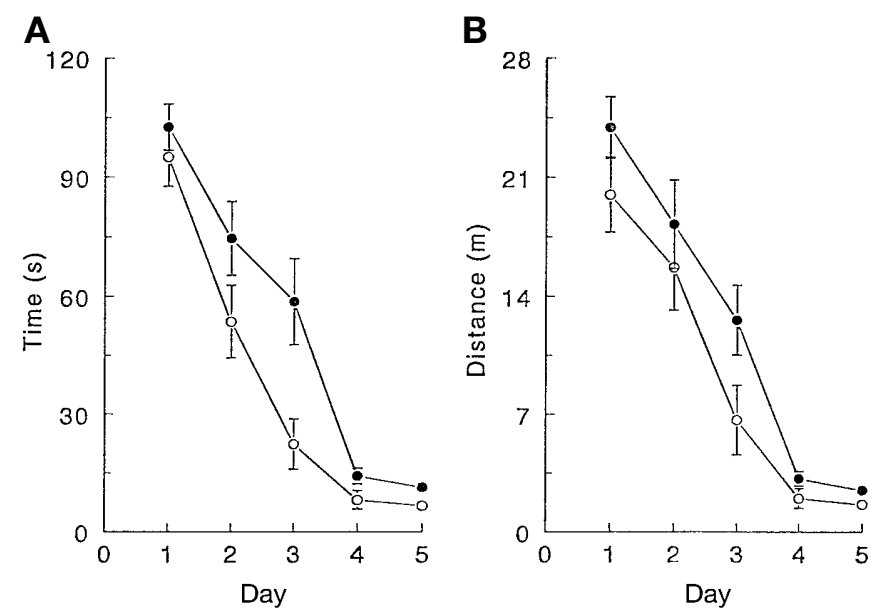

Fig. 2 A, B. Morris water maze learning in young adult animals. A The time (s) swum to reach the platform during 5 consecutive days of training in control $(\bigcirc, n=9)$ and diabetic $(O$, $n=9)$ rats. Control rats performed better than diabetic rats: ANOVAR (day 1-5): $F(1.16)=5.77, p<0.05$. B The distance $(\mathrm{m})$ swum by the rats to reach the platform. The control animals performed better in the last 3 days of the experiment: ANOVAR (day 3-5): $F(1.16)=4.77, p<0.05$

Experiment 2. In aged control rats the latency and distance swum to reach the platform did not show the rapid improvement as seen in young adult rats (Fig.3). Still, latencies and distance swum decreased gradually during the 8 days of training. Like in young adults, the performance of diabetic rats was impaired compared with controls (day 1-8: latencies: $p=0.08$; distance: $p<0.05$ ). Latencies to reach the platform were higher in diabetic animals than in controls during the final 3 days of the testing $(p<0.05)$. Performance of diabetic and non-diabetic aged rats in the trial with the visible platform was similar (latencies $27.1 \pm 4.7$ and $26.6 \pm 7.9 \mathrm{~s}$ and distances $4.6 \pm 1.1$ and $4.4 \pm 15 \mathrm{~m}$, in control and diabetic rats, respectively).

\section{Hippocampal electrophysiology}

Experiment 1. The average baseline slope of the fEPSPs was $0.40 \pm 0.01$ and $0.42 \pm 0.01 \mathrm{mV} / \mathrm{ms}$ in hippocampal slices from control and diabetic animals, respectively (NS). A $1 \mathrm{~Hz}$ train of 900 stimuli resulted in depression of the synapses to $91.8 \pm 2.8 \%$ of the baseline values in slices from control and $78.5 \pm 01.8 \%$ in young adult diabetic rats (Fig. $4 ; p<0.05$ control vs diabetic). Responses recorded $30 \mathrm{~min}$ after a $100 \mathrm{~Hz}$ train of 900 stimuli were potentiated to $217.7 \pm$ $14.4 \%$ of the baseline value in slices from control and $137.7 \pm 5.5 \%$ in diabetic rats (Fig. $4 ; p<0.05$ control vs diabetic). In both groups 5,10 and $50 \mathrm{~Hz}$ trains of conditioning stimuli induced mild depression, no change, and slight potentiation of the synapses, respectively (Fig. 4; control vs diabetic, NS).
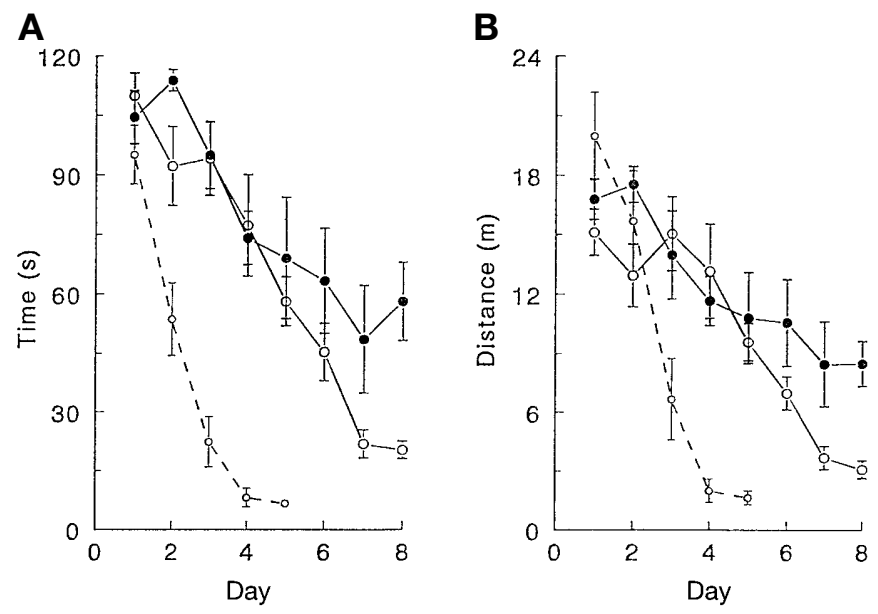

Fig.3A, B. Morris water maze learning in aged animals. A The time (s) swum to reach the platform during 8 consecutive days of training in control $(\bigcirc, n=6)$ and diabetic $(O, n=7)$ rats. Control rats performed better than diabetic rats: ANOVAR (day 1-8): $F(1.11)=3.66, p=0.08$. ANOVAR (day 6-8): $F(1.11)=5.33, p<0.05$. Both groups showed longer latencies to reach the platform than the young adult control animals (interrupted line). B The distance (m) swum by the rats to reach the platform. The performance of diabetic rats was impaired ANOVAR (day 1-8): $F(1.11)=5.29, p<0.05$. Note the difference in comparison to the distances swum by the young adult control animals (interrupted line)

Experiment 2. The average baseline slope of the fEPSPs was $0.43 \pm 0.01$ and $0.51 \pm 0.02 \mathrm{mV} / \mathrm{ms}$ in hippocampal slices from control and diabetic animals, respectively $(p<0.05)$. There was generally more depression of the synapses in response to LFS (1, 5 and $10 \mathrm{~Hz}$ ) in slices from diabetic animals than in controls (Fig. 5). The slope of the fEPSP in control slices was $91.8 \pm 1.8 \%$ of the baseline value, $30 \mathrm{~min}$ after the $1 \mathrm{~Hz}$ stimuli train, whereas in slices from diabetic animals it was $74.1 \pm 1.9 \%$ of baseline $(p<0.05$ control vs diabetic). The slopes of the fEPSP in slices from diabetic rats $30 \mathrm{~min}$ after $5 \mathrm{~Hz}$ and $10 \mathrm{~Hz}$ conditioning stimuli were depressed compared with baseline values $(p<0.05)$. No significant depression was measured in control slices using the same protocols. A significant difference was measured between the two groups $(p<0.05)$. The $100 \mathrm{~Hz}$ stimulus train induced significant potentiation of the fEPSP slope in control slices (148.4 $\pm 48.6 \%$ of baseline) but no significant increase in the fEPSP slope was observed in diabetic slices $(p<0.05$ control vs diabetic). No significant potentiation of the synapses was measured in either group when the frequency of the stimulus train was $50 \mathrm{~Hz}$.

\section{Discussion}

Our study shows that both STZ diabetes and ageing affect the brain. In young adult rats, 8 weeks of STZ diabetes led to modest learning deficits and moderate 


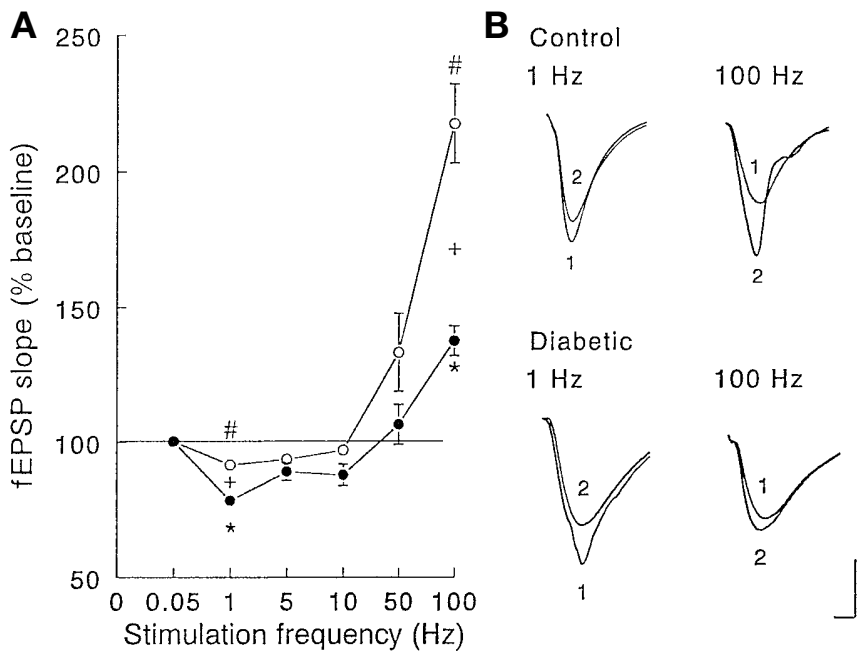

Fig.4. A Relative fEPSP slopes after different conditioning stimuli in hippocampal slices from young adult animals. Low frequency conditioning stimuli induced depression of the fEPSP whereas HFS induced potentiation. Significant changes in the fEPSP slop within each group are indicated (\#: $p<0.05$ within the control group $(\bigcirc, n=8)$ : $* p<0.05$ within the diabetic group [O, $n=8])$. Compared with controls, expression of LTD at $1 \mathrm{HZ}$ stimulation was significantly enhanced in diabetic slices, whereas expression of LTP at $100 \mathrm{~Hz}$ stimulation was significant impaired $\left({ }^{+} p<0.05, t\right.$ test $)$. B Traces represent 15 averaged fEPSPs recorded before (1) and 30 min after (2) the application of $1 \mathrm{~Hz}$ or $100 \mathrm{~Hz}$ conditioning stimulus. Horizontal scale bar represents $5 \mathrm{~ms}$, vertical scalebar $1 \mathrm{mV}$

alterations in hippocampal synaptic plasticity. In nondiabetic aged rats, water maze learning was considerably impaired compared with young adult, non-diabetic rats, as was synaptic plasticity. When diabetes and ageing were combined, a further impairment of learning and plasticity was observed.

Morris-water maze performance in aged non-diabetic rats was severely impaired compared with young adult controls, in line with previous observations [22-25]. This performance deficit is considered to reflect impaired comprehension of the task and difficulties in learning the location of the platform. Although sensorimotor deficits could account for part of the deficit, they are unlikely to have a major role. Swimming distances were higher in the aged rats than in young adults from day 3 onwards, indicating that the increased latency to reach the platform was due to an inefficient search pattern, rather than to difficulties with swimming. Moreover. visual Cues around the maze were obscured, to exclude involvement of visual impairments.

In concordance with the learning impairment, hippocampal synaptic plasticity was disturbed in the aged non-diabetic animals compared with young adults. Both LTP and LTD induction were affected. Although significant potentiation of the fEPSP slope was recorded after HFS in slices from aged rats, LTP expression was significantly lower than in the young

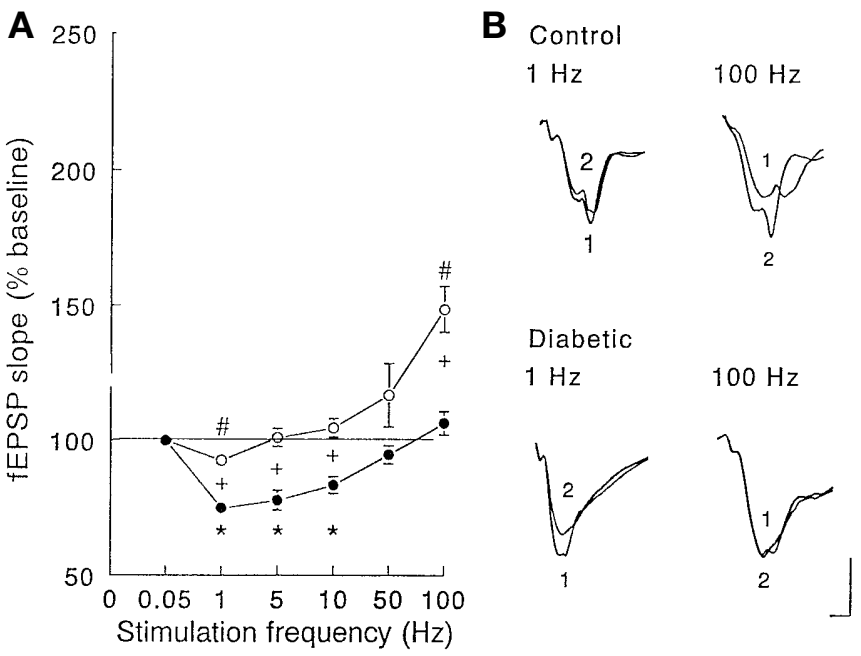

Fig. 5. A Relative fEPSP slopes after different conditioning stimuli in hippocampal slices from aged animals. Significant changes in the fEPSP slope within each group are indicated ( $\left.{ }^{\#} p<0.05\right)$ within the control group $(\bigcirc, n=8) ; * p<0.05$ within the diabetic group $(\bigcirc, n=7)$. Compared with controls, expression of LTD was significantly enhanced in diabetic slices after 1,5 and $10 \mathrm{~Hz}$ stimuli $\left({ }^{+} p<0.05, t\right.$ test), whereas expression of LTP after $100 \mathrm{~Hz}$ stimulation was significantly impaired $\left({ }^{+} p<0.05\right)$. B Traces represent 15 averaged fEPSPs recorded before (1) and $30 \mathrm{~min}$ after (2) the application of $1 \mathrm{~Hz}$ or 100 $\mathrm{Hz}$ conditioning stimulus

adult animals. The effects of ageing on hippocampal synaptic plasticity have been studied previously. Significant LTP induction has been shown in rats up to 20-24 months of age, but LTP induction and maintenance in younger animals was easier and proved to be more stable $[13,26]$. It has been suggested that potentiation deficits in aged rats can only be detected with brief trains of HFS (less than 50 pulses) [27, 28]. Significant LTP deficits have, however, also been reported using trains of HFS of longer duration (e.g. 225 pulses [29]), corresponding with our findings. In our study LFS elicited small but statistically significant depression of the fEPSP slopes, which was similar in both age groups. Controversy exists on the effects of development and ageing on LTD. During maturation, induction of LTD is increasingly difficult [30-33]. Some authors report, however, a shift towards facilitation of LTD induction at advanced age [34].

Impaired performance of young adult diabetic rats in the water maze has been shown previously $[10,12]$. This performance deficit is considered to be due to impaired comprehension of the task and difficulties in learning the location of the platform. Notably, when task difficulty is reduced, by non-spatial pretraining sessions, diabetic rats perform as well as non-diabetic rats, showing that cognitive impairments rather than sensorimotor deficits determine the performance deficit [12]. This is supported by the present observation that the performance of diabetic rats of both age groups was similar to controls 
in the task with the visible platform. The impaired performance of diabetic rats was shown previously to be related to diabetes duration [12]. This accounts for the relative modest performance deficit in the present study, which deliberately used a shorter diabetes duration than previous studies, to show any added effect of ageing in experiment 2.

The observation that 8 weeks of STZ diabetes affects LTP induction in young adult rats is in line with previous observations $[10,11,35]$. Our results confirm our previous report that severe hyperglycaemia enhanced the induction and maintenance of LTD [11]. Others, however, found no LTD defects in STZ-induced diabetic rats. This latter finding could be due to differences in the LTD induction protocol because the investigators used a $5-\mathrm{Hz}$ stimulus train of 5 min duration. In the present experiment LTD induction in young adult control and diabetic rats was also similar at $5 \mathrm{~Hz}$.

The learning and plasticity deficits in STZ diabetic rats are less severe in moderately hyperglycaemic animals $[10,36]$ and can be prevented, but not reversed, by insulin treatment [12]. These latter findings indicate that the observed deficits are not due to a direct toxic effect of streptozotocin on the brain. Moreover, STZ transport and cytotoxicity is dependent on expression of the GLUT2 glucose transporter [37], which is not expressed at the blood-brain barrier in rats [38].

The diabetes induction protocol was different in young adult and aged animals because pilot studies showed that a STZ dose of $33 \mathrm{mg} / \mathrm{kg}$ was fatal in aged rats. This finding is in line with previous observations of increased STZ toxicity with advancing age in rats [39]. Despite differences in the diabetes induction protocol, random and fasting blood glucose concentrations, oral glucose tolerance and $\mathrm{HbA}_{1}$ values were similar in both groups, suggesting that diabetes was of similar severity in both age groups.

Diabetes aggravated the effects of ageing on water maze performance and on hippocampal synaptic plasticity. In the water maze on the final days of testing, the latency and distance swum to reach the platform in the aged diabetic rats were twice as high as in the aged control animals. In these same animals, alterations in synaptic plasticity were also most pronounced. In contrast to the other three experimental groups, no LTP could be induced in aged diabetic rats. In addition, LTD was significantly higher than in the other three groups: in response to $1 \mathrm{~Hz}$ stimulation, the slices taken from aged diabetic rats had higher depression of the synapses than the other groups. Moreover, significant LTD was induced by 5 and $10 \mathrm{~Hz}$ LFSs, which failed to induce LTD in young adult and aged control animals and in young adult diabetic rats.

Accelerated cognitive decline due to the combination of ageing on diabetes could be due to added effects of aetiologically unrelated disorders. More likely is, however, that there is an aetiological interaction be- cause the pathogenesis of brain ageing and the pathogenesis of diabetic complications shows considerable similarities. For example, oxidative stress is enhanced in both diabetes and ageing, as is the production of advanced glycation end products [17, 18]. Moreover, both ageing and diabetes are associated with microvascular changes in the brain [40,41]. In addition, neuronal $\mathrm{Ca}^{2+}$ homeostasis is disturbed in both diabetes [17] and ageing [42, 43]. This disturbed $\mathrm{Ca}^{2+}$ homeostasis could be involved in the plasticity deficits observed, as LTP and LTD are calcium-dependent processes and the balance between LTP and LTD induction seems to be modulated by intracellular $\mathrm{Ca}^{2+}$ concentrations $[8,9]$. In experimental models for ageing, as well as in models for diabetes, hippocampal synapses show plasticity modifications favouring LTD induction $[11,34,44]$, whereas LTP expression and maintenance is impaired $[11,45]$. In ageing rats, it was shown that an increase in $\mathrm{Ca}^{2+}$ influx through L-type voltagedependent $\mathrm{Ca}^{2+}$ channels can lower the LTD induction threshold [26]. Moreover, this $\mathrm{Ca}^{2+}$ influx would also impair LTP induction by the activation of the $\mathrm{Ca}^{2+}$-dependent, K-mediated after-hyperpolarisation [26].

In line with clinical observations, cognitive deficits were shown in diabetic rats, which were aggravated by ageing. In addition, diabetic and aged rats expressed pronounced alterations in synaptic plasticity, presenting a possible neuronal correlate for the cognitive deficits. The cumulative deficits in learning and synaptic plasticity in aged diabetic rats indicate that the effects of diabetes and ageing on the brain could interact. The experimental model presented in this study can be used to study the pathophysiology of the complex interaction between diabetes and ageing. Better understanding of this interaction may eventually challenge the concept of accelerated cognitive decline in elderly diabetic patients as an irremediable disorder [16].

Acknowledgements. This research is supported by grant 96125H from the Dutch Diabetes Foundation.

\section{References}

1. Biessels GJ, Kappelle AC, Bravenboer B, Erkelens DW, Gispen WH (1994) Cerebral function in diabetes mellitus. Diabetologia 37: 643-650

2. Ryan CM (1988) Neurobehavioral complications of type I diabetes. Examination of possible risk factors. Diabetes Care 11: 86-93

3. Tun PA, Nathan DM, Perlmuter LC (1990) Cognitive and affective disorders in elderly diabetics. Clin Geriatr Med 6: 731-746

4. Croxson SCM, Jagger C (1995) Diabetes and cognitive impairment: a community based study of elderly subjects. Age Ageing 24: 421-424

5. Kalmijn S, Feskens EJM, Launer LJ, Stijnen T, Kromhout D (1995) Glucose intolerance, hyperinsulinaemia and cognitive function in a general population of elderly men. Diabetologia 38: 1096-1102 
6. Eichenbaum H, Otto T, Cohen NJ (1992) The hippocampus - what does it do? Behav Neural Biol 57: 2-36

7. Bunsey M, Eichenbaum H (1996) Conservation of hippocampal memory function in rats and humans. Nature 379: 255-257

8. Bliss TV, Collingridge GL (1993) A synaptic model of memory: long-term potentiation in the hippocampus. Nature 361: 31-39

9. Malenka RC (1994) Synaptic plasticity in the hippocampus: LTP and LTD. Cell 78: 535-538

10. Biessels GJ, Kamal A, Ramakers GM et al. (1996) Place learning and hippocampal synaptic plasticity in streptozotocin-induced diabetic rats. Diabetes 45: 1259-1266

11. Kamal A, Biessels GJ, Urban IJA, Gispen WH (1999) Hippocampal synaptic plasticity in streptozotocin-diabetic rats: impairment of long-term potentiation and facilitation of long-term depression. Neuroscience 90: 737-745

12. Biessels GJ, Kamal A, Urban IJ, Spruijt BM, Erkelens DW, Gispen WH (1998) Water maze learning and hippocampal synaptic plasticity in streptozotocin-diabetic rats: effects of insulin treatment. Brain Res 800: 125-135

13. Barnes CA (1994) Normal aging: regionally specific changes in hippocampal synaptic transmission. Trends Neurosci 17: $13-18$

14. Davis S, Butcher SP, Morris RG (1992) The NMDA receptor antagonist D-2-amino-5-phosphonopentanoate (DAP5) impairs spatial learning and LTP in vivo at intracerebral concentrations comparable to those that block LTP in vitro. J Neurosci 12: 21-34

15. Grant SG, O’Dell TJ, Karl KA, Stein PL, Soriano P, Kandel ER (1992) Impaired long-term potentiation, spatial learning, and hippocampal development in fyn mutant mice. Science 258: 1903-1910

16. Stewart R, Liolitsa D (1999) Type 2 diabetes mellitus, cognitive impairment and dementia. Diabet Med 16: 93-112

17. Biessels GJ, Gispen WH (1996) The calcium hypothesis of brain aging and neurodegenerative disorders: significance in diabetic neuropathy. Life Sci 59: 379-387

18. Smith MA, Sayre LM, Monnier VM, Perry G (1995) Radical AGEing in Alzheimer's disease. Trends Neurosci 18: 172-176

19. Van Dam PS, Van Asbeck BS, Erketens DW, Marx JJM, Gispen WE, Bravenboer B (1995) The role of oxidative stress in neuropathy and other diabetic complications. Diabetes Metab Rev 11: 181-192

20. McNamara R, Skelton RW (1993) The neuropharmacological and neurochemical basis of place learning in the Morris water maze. Brain Res Brain Res Rev 18: 33-49

21. Dudek SM, Bear MF (1992) Homosynaptic long-term depression in area CA1 of hippocampus and effects of N-methyl-D-aspartate receptor blockade. Proc Natl Acad Sci USA 89: 4363-4367

22. Lynch MA, Voss KL, Gower AJ (1994) Impaired spatial memory in aged rats is associated with alterations in mositol phospholipid metabolism. Neuroreport 5: 1493-1497

23. Diana G, Domenic MR, Scotti de Carolis A, Loizzo A, Sagratella S (1995) Reduced hippocampal CA1 Ca(2+)-induced long-term potentiation is associated with age-dependent impairment of spatial teaming. Brain Res 686: 107-110

24. Granger R, Deadwyler S, Davis M, Moskovitz B, Kessler M, Rogers G et al. (1996) Facilitation of glutamate receptors reverses an age-associated memory impairment in rats. Synapse 22: 332-337

25. Diana G, Scotti de Carolis A, Frank C, Domenici MR, Sagratella S (1994) Selective reduction of hippocampal dentate frequency potentiation in aged rats with impaired place learning. Brain Res Bull 35: 107-111
26. Norris CM, Halpain S, Foster TC (1998) Reversal of agerelated alterations in synaptic plasticity by blockade of Ltype Ca2+channels. J Neurosci 18: 3171-3179

27. Moore CI, Browning MD, Rose GM (1993) Hippocampal plasticity induced by primed burst, but not long-term potentiation, stimulation is impaired in area CA1 of aged Fischer 344 rats. Hippocampus 3: 57-66

28. Deupree DL, Bradley J, Turner DA (1993) Age-related alterations in potentiation in the CA1 region in $\mathrm{F} 344$ rats. Neurobiol Aging 14: 249-258

29. Thielen AM, Mollevanger WJ, Lopez Da Silva FH, Hollander CF (1983) Neuronal plasticity in hippocampal slices of extremely old rats. In: Gispen WH, Traber J (eds) Aging of the brain. Elsevier, Amsterdam, pp 73-84

30. Wexler EM, Stanton PK (1993) Priming of homosynaptic long-term depression in hippocampus by previous synaptic activity. Neuro Report 4: 591-594

31. Wagner JJ, Alger BE (1995) GABAergic and developmental influences on homosynaptic LTD and depotentiation in rat hippocampus. J Neurosci 15: 1577-1586

32. Errington ML, Bliss TV, Richter-Levin G, Yenk K, Doyere V, Laroche S (1995) Stimulation at $1-5 \mathrm{~Hz}$ does not produce long-term depression or depotentiation in the hippocampus of the adult rat in vivo. J Neurophysiol 74: 1793-1799

33. Kamal A, Biessels GJ, Gispen WH, Urban IJA (1998) Increasing age reduces expression of LTD and dynamic range of transmission plasticity in CA1 field of the rat hippocampus. Neuroscience 83: 707-715

34. Norris CM, Korol DL, Foster TC (1996) Increased susceptibility to induction of long-term depression and long-term potentiation reversal during aging. J Neurosci 16: 5382-5392

35. Chabot C, Massicotte G, Milot M, Trudeau F, Gagne J (1997) Impaired modulation of AMPA receptors by calcium-dependent processes in streptozotocin-induced diabetic rats. Brain Res 768: 249-256

36. Tekkök S, Kmjevic K (1999) Diabetes mellitus preserves synaptic plasticity in hippocampal slices from middle-aged rats. Neuroscience 91: 185-191

37. Schnedl WJ, Ferber S, Johnson JH et al. (1994) STZ transport and cytotoxicity. Specific enhancement in GLUT2-expressing cells. Diabetes 43: 1326-1333

38. Simpson IA, Appel NM, Hokari M et al. (1999) Bloodbrain barrier glucose transporter: effects of hypo-and hyperglycemia revisited. J Neurochem 72: 238-247

39. Kappelle AC, Bravenboer B, van Buren T, Traber J, Erkelens DW, Gispen WH (1993) Amelioration by the Ca2 + antagonist, nimodipme of an existing neuropathy in the streptozotocin-induced, diabetic rat. Br J Pharmacol 108: 780-785

40. Mankosky BN, Metzger BE, Molitch ME, Biller J (1997) Cerebrovascular disorders in patients with diabetes mellitus. J Diabetes Complications 10: 228-242

41. De Jong GI, De Vos RA, Steur EN, Luiten PG (1997) Cerebrovascular hypoperfusion: a risk factor for Alzheimer's disease? Animal model and postmortem human studies. Ann NY Acad Sci 826: 56-74

42. Disterhoft JF, Moyer JR, Jr, Thompson LT (1994) The calcium rationale in aging and Alzheimer's disease. Evidence from an animal model of normal aging. Ann NY Acad Sci 747: 382-406

43. Khachaturian ZS (t994) Calcium hypothesis of Alzheimer's disease and brain aging. Ann NY Acad Sci 747: 1-11

44. Foster TC, Norris CM (1997) Age-associated changes in $\mathrm{Ca}(2+)$-dependent processes: relation to hippocampal synaptic plasticity. Hippocampus 7: 602-612

45. DeToledo-Morrell L, Geinisman Y, Morrell F (1988) Agedependent alterations in hippocampal synaptic plasticity: relation to memory disorders. Neurobiol Aging 9: 581-590 